\title{
Psychometric Properties of Podsakoff's Organizational Citizenship Behaviour Scale in the Asian Context
}

\author{
Mohd. Muzamil Kumar ${ }^{1 *}$, Shawkat Ahmad Shah ${ }^{2}$
}

\section{ABSTRACT}

The Organizational Citizenship Behavior Scale developed by Podsakoff, et al.(1990) has mostly been found to have better psychometric properties in the western countries mainly North America and there is a dearth of studies that portray the meaningfulness \& relevance of using this measure in the Asian cultural contexts. The present study was thus aimed at checking the psychometric properties of this scale on a sample of permanent professionals working at the three main human service organizations operating in Srinagar, J\&K (University of Kashmir, S.K.I.M.S Hospital \& J\&K Bank). After preliminary analysis, exploratory and confirmatory factor analysis was carried out and three dimensional factor structure of organizational citizenship behavior was revealed. The reliability and validity of the brief version of the scale was found to be satisfactory, thereby providing support for the relevance of using this scale in the Asian context.

Keywords: OCB, Human Service Professionals, Factor Structure.

The concept of organizational citizenship behaviour (OCB) has been studied since 1970.Dennis Organ, who is considered as the father of OCB actually expanded upon Katz's (1964) original work. Organ (1988) defines OCB as "individual behavior that is discretionary, not directly or explicitly recognized by the formal reward system, and that in the aggregate promotes the effective functioning of the organization". A careful analysis of this definition firstly reveals that OCB is a discretionary behavior performed on the basis of choice and not a part of job description, secondly it means going beyond the enforceable requirements of job description and finally it positively impacts the organizational effectiveness. The construct has been studied in a diversity of disciplines such as marketing, human resources management, health care economics \& psychology (Lievens \& Anseel, 2004). Several OCB models have been developed by researchers since the origin of the concept, however there are five dimensions of OCB that are very frequently recognized in existing research(LePine, Erev \& Johnson, 2002) which include altruism, courtesy, civic virtue, sportsmanship and conscientiousness. Altruism in the workplace consists essentially of helping behaviors which can be directed within or outside of the

\footnotetext{
${ }^{1}$ Ph. D Scholar, Department of Psychology, University of Kashmir, Hazratbal, Srinagar, J\&K

${ }^{2}$ Associate Professor, Department of Psychology, University of Kashmir, Hazratbal, Srinagar, J\&K *Corresponding Author

(C) 2015 I M Kumar, S Shah; licensee IJIP. This is an Open Access Research distributed under the terms of the Creative Commons Attribution License (http://creativecommons.org/licenses/by/2.0), which permits unrestricted use, distribution, and reproduction in any Medium, provided the original work is properly cited.
} 


\section{Psychometric Properties of Podsakoff's Organizational Citizenship Behaviour Scale in the Asian Context}

organization. There is no direct link, or one-to-one relationship, between every instance of helping behavior and a specific gain for the organization but over time, the compilation of employees helping behavior proves advantageous for the organization. (Organ et al., 2006).Courtesy has been defined as discretionary behavior that aims at preventing work-related conflicts with other personnel (Law et al., 2005). This dimension is a form of helping behavior, but one that works to prevent problems from arising and includes the word's literal definition of being polite and considerate of others (Organ et al., 2006). Civic virtue is characterized by behaviors that indicate the employee's deep concerns and active interest in the life of the organization (Law et al., 2005). This dimension also encompasses positive involvement in the concerns of the organization (Organ et al., 2006). Examples of civic virtue can be seen in daily affairs like attending meetings; staying updated with organizational announcements and defending the organization's policies and practices when they are challenged by an outside source. The conscientiousness includes adherence to organizational rules/ norms and it depicts the reliability and dependability of the employee within the organization. Finally, sportsmanship has been defined as willingness on the part of the employee that signifies the employee's tolerance of less-than-ideal organizational circumstances without complaining and blowing problems out of proportion. Organ et al. (2006) further defined sportsmanship as an employee's "ability to roll with the punches" even if they do not like or agree with the changes that are occurring within the organization. By reducing the amount of complaints from employees that administrators have to deal with, sportsmanship conserves time and energy. Many measures have been used to assess these OCB dimensions from time to time, the scale developed by (Podsakoff,et al. 1990) is one of the most cited scales in the researches done in western context and it has been found to have satisfactory psychometric properties as demonstrated in past studies (MacKenzie et al., 1999; MacKenzie et al., 1998; Podsakoff \& MacKenzie, 1994; MacKenzie et al., 1993). Considering that in the Indian context there is dearth of studies which have established the reliability and validity of this measure, the present study aimed at investigating the same on a sample group of professionals of human service organizations functioning in Srinagar, J\&K.

\section{METHOD}

\section{Sample Size}

The participants of the study included 360 professionals in the form of Doctors, Higher Education Teachers \& Bank Officers selected randomly from the three major organizations delivering the human service in Kashmir namely, University of Kashmir, S.K.I.M.S. Hospital (Soura,Srinagar) and the J\&K Bank branches. All the professionals were working on the permanent basis at the mentioned organizations.

\section{Research Instrument}

The 24 item scale developed by (Podsakoff, 1990) was adopted and checked in terms of its psychometric properties. However as Podsakoff et al.(2006) stresses the consideration of cultural 


\section{Psychometric Properties of Podsakoff's Organizational Citizenship Behaviour Scale in the Asian Context}

context while operational sing the construct of organizational citizenship behavior, all the 24 items of this scale were subjected to pilot testing which included an initial reliability test that was conducted on $15 \%$ of the total sample size. This was followed discussion of the each item with respondents and organizational psychology experts. Accordingly the items that were found to have a lack of internal consistency or reported by the respondents and experts as contextually vague, irrelevant, ambiguous or confusing were dropped or slightly modified to provide clarity and precision. Finally 15 items from the adopted scale (as shown in table 2.1) were incorporated in the present study for subsequent analysis and the responses for the same were collected from the participants via questionnaire based on a seven point Likert scale with 1 = Strongly Disagree and 7= Strongly Agree.

Table 2.1.Showing items of the measuring instrument

I willingly help fellow professionals when they have work related problems.

Altruism: I willingly help new comers to get oriented towards job.

I am always ready to lend a helping hand to those around me.

I always try to avoid creating problems for co-workers.

Courtesy: I am mindful of how my behaviour affects other people’s jobs.

I don't abuse the rights of others.

I always keep myself abreast of changes in the organization.

Civic Virtue: I keep myself updated with organizational announcements \& memos.

I attend meetings that aren't compulsory but help my department anyway.

I always require frequent doses of motivation to get the work done.

Sportsmanship: I usually find fault with what my organization is doing.

I usually focus on what is wrong rather than positive side of situation

I obey organizational rules even when no one is watching.

Conscientiousness: I don't take extra or long breaks while on duty.

My attendance at work is above the norm.

\section{Data Analysis}

As establishing factor structure needs application of multivariate statistical techniques, the data was subject to screening, primarily, using SPSS (version 20). The screening included an examination of means, standard deviations, standard errors, skewness and kurtosis in order to 


\section{Psychometric Properties of Podsakoff's Organizational Citizenship Behaviour Scale in the Asian Context}

ensure normality of the data. The removal of outliers was ensured subject to their impact on normality after which only 340 response sheets were deemed fit for subsequent analysis. This was followed by Exploratory \& Confirmatory Factor Analysis procedures. Exploratory Factor analysis was carried out by SPSS (version 20) and in case of confirmatory factor analysis AMOS (Version 20) was made use of.

\section{RESULTS \& DISCUSSION}

\section{Table 1 Description of Sample Group}

\begin{tabular}{lllll}
\hline $\begin{array}{l}\text { Demographic } \\
\text { Variable }\end{array}$ & Groups & f & $\%$ & Total \\
\hline Designation & University Teachers & 156 & 45.90 & 340 \\
& S.K.I.M.S. Consultants & 090 & 26.50 & \\
& J\&K Bank Officers & 094 & 27.60 & \\
\hline Gender & Male & 246 & 72.40 & 340 \\
& Female & 094 & 27.60 & \\
\hline Age (Years) & $>35$ & 110 & 32.40 & \\
& $36-45$ & 102 & 30.00 & 340 \\
& $46-55$ & 091 & 26.80 & \\
& $56 \&$ above & 037 & 10.80 & \\
\hline Length of Service & $>5$ & 091 & 26.76 & \\
& $6-15$ & 126 & 37.06 & 340 \\
& $16-25$ & 089 & 26.18 & \\
& 26\&above & 034 & 10.00 & \multirow{2}{*}{340} \\
\hline Marital Status & Married & 273 & 80.30 & \\
& Unmarried & 067 & 19.70 & 340 \\
\hline Salary & up to 40000 & 057 & 16.76 & \\
& $40000-80000$ & 169 & 49.71 & \\
& 80000-120000 & 082 & 24.12 & \\
& 120000 \& above & 032 & 09.41 & \\
\hline
\end{tabular}

The table 1 provides the description of sample group in terms of various demographic variables. This information ensures that the respondents represent diverse organizations and individuals differing in various aspects. Pertinently Alexender (1995) has also highly emphasized the importance of demographic information. 
Table 2 Descriptive Statistics for dimensions of OCB. $(N=340)$

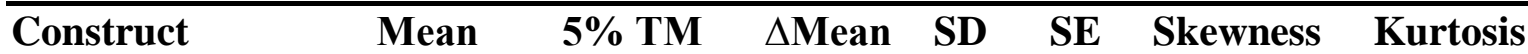

\begin{tabular}{lccccccc}
\hline Altruism & 6.33 & 6.40 & 0.07 & 0.68 & 0.03 & -1.2 & 1.9 \\
Courtesy & 6.34 & 6.42 & 0.08 & 0.71 & 0.03 & -1.4 & 1.9 \\
Civic Virtue & 5.63 & 5.67 & 0.04 & 0.89 & 0.04 & -0.6 & 0.7 \\
Sportsmanship & 4.62 & 4.66 & 0.04 & 1.3 & 0.07 & -0.3 & -0.4 \\
Compliance. & 6.14 & 6.24 & 0.10 & 0.86 & 0.04 & -1.3 & 1.8 \\
OCB & 5.81 & 5.83 & 0.02 & 0.54 & 0.02 & -0.5 & 0.3 \\
\hline
\end{tabular}

SD (Standard deviation); SE(Standard error); TM(Trimmed Mean).

As per the above table the sample distribution of the present study is considered normal as no skewness \& kurtosis value falls beyond the range of -2.00 to +2.00 recommended by Garson(2009).Besides this the $\Delta$ Mean(difference between mean and 5\% trimmed mean) is not beyond the criteria of $>0.20$ suggested by Pallant (2007).

Table 3 Reliability Test Results of the measure of Organizational Citizenship Behaviour.

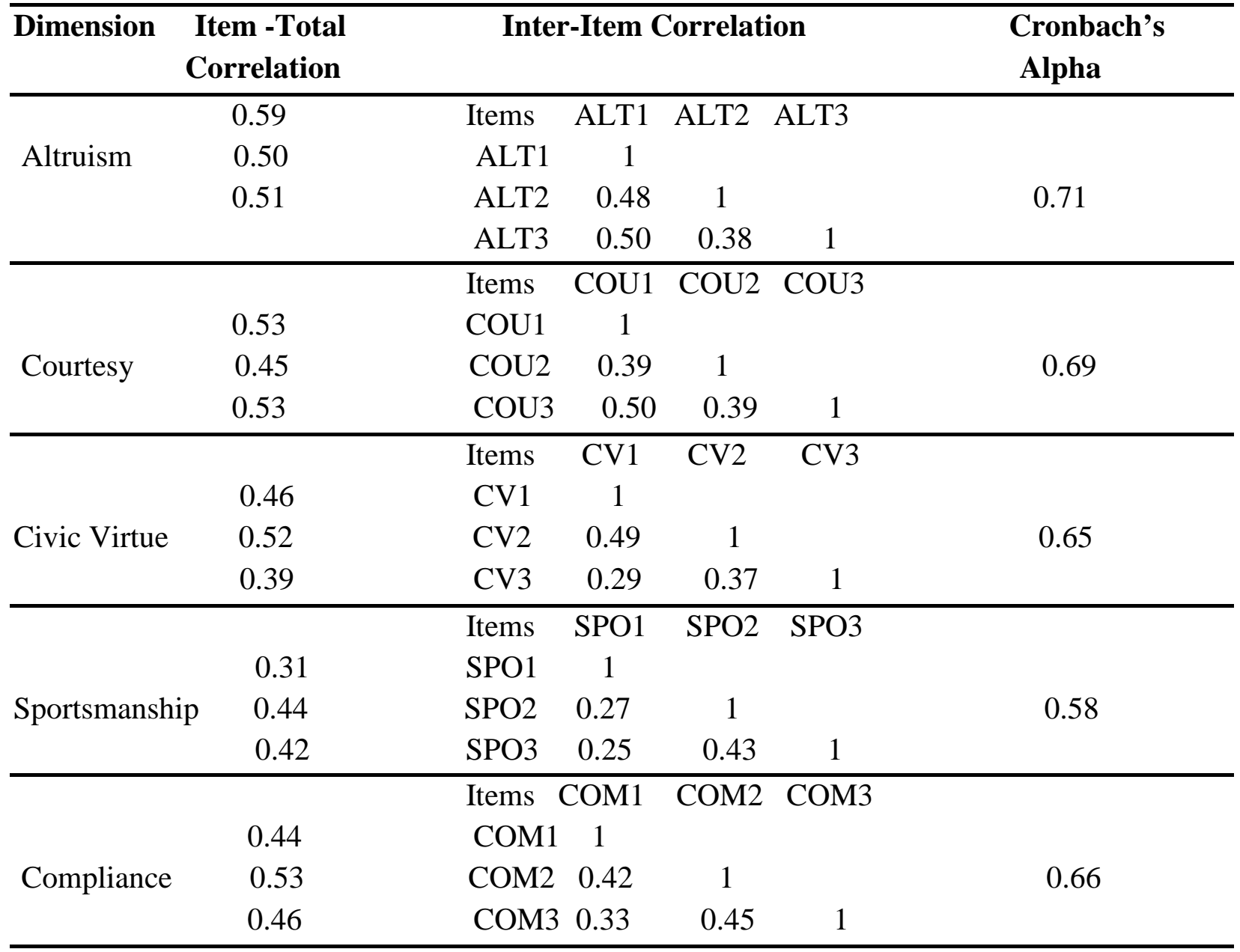


ALT1-ALT3= Altruism; COU1-COU3= Courtesy; CV1-CV3= Civic Virtue ; SPO1-SPO3= Sportsmanship; COM1- COM3= Complaince.

Table 3 depicts the results of the reliability test that was conducted to assess the degree of consistency among the multiple measurement of the variable. As per Everitt(2002) and Field(2005) item - total correlation should be beyond 0.2 or 0.3 . As per guidelines of Saxe \& Weltz(1982) item-total correlations more than or equal to 0.35 are acceptable. Yong, Hua \& Mei(2007) stated that in case Cronbach's alpha a value greater than 0.6 is acceptable. After juxtaposing the results of reliability tests with the said guidelines items pertaining to sportsmanship dimension were not considered for subsequent analysis.

Table 4 Rotated Component Matrix after carrying Exploratory Factor Analysis of the items of OCB Measure. $K M O=0.80$; Bartletts test of sphericity $=1028.23$, signicance $=.0001$

\begin{tabular}{|c|c|c|c|c|}
\hline $\begin{array}{c}\text { Items } \\
\quad \downarrow\end{array}$ & Components $\rightarrow$ & I & II & III \\
\hline$\overline{\text { ALT1 }}$ & & 0.75 & & \\
\hline ALT2 & & 0.73 & & \\
\hline ALT3 & & 0.61 & & \\
\hline COU1 & & 0.76 & & \\
\hline COU2 & & 0.60 & & \\
\hline COU3 & & 0.62 & & \\
\hline CV1 & & & & 0.70 \\
\hline CV2 & & & & 0.77 \\
\hline CV3 & & & & 0.73 \\
\hline COM1 & & & 0.70 & \\
\hline COM2 & & & 0.79 & \\
\hline COM3 & & & 0.76 & \\
\hline
\end{tabular}

ALT1-ALT3= Altruism; COU1-COU3= Courtesy; CV1-CV3= Civic Virtue ; SPO1-SPO3= Sportsmanship; COM1- COM3= Complaince.

The above table depicts adequate sampling adequacy \& significant Bartlet's test of sphericity at 0.0001 level of significance. By using a varimax rotation with method of principle component analysis \& Kaiser's criteria, a three factor structure of organizational citizenship behaviour was revealed. All loadings were significant and above the minimum threshold of 0.50 \& represented $55.66 \%$ of the variance. Considering that the respondents perceived altruism \& courtesy as the same construct, the three factors were named as Helping Behaviour, civic virtue and compliance as per the guidelines of Podsakoff \& Mackenzie(1994) and Khalid(2009).However this finding doesn't leave a question mark over the discriminant validity of the OCB construct but simply reveals its factor structure in context of sample group of the present study. 
Fig 1. Measurement model of OCB Dimensions

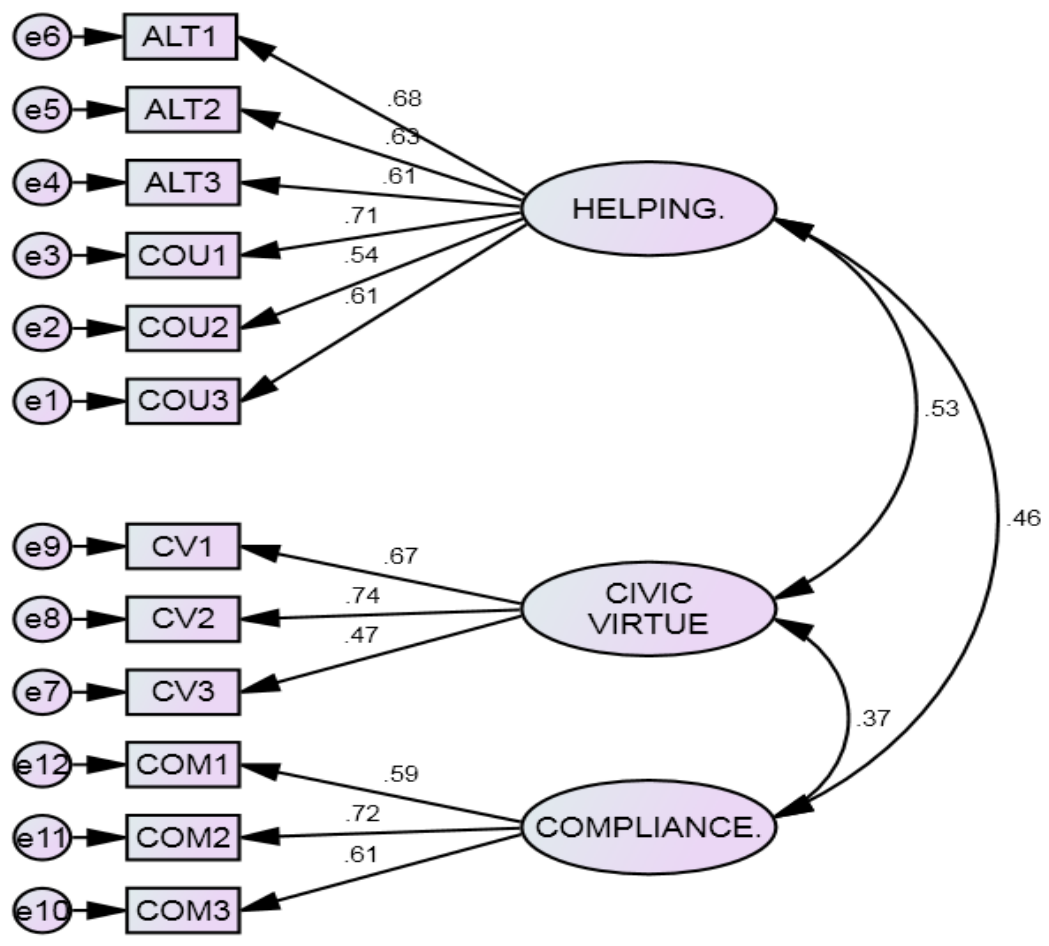

After exploratory factor analysis, a confirmatory factor analysis was carried out, the results of which are portrayed in figure 1. CFA ensures checking for both convergent validity \& discrimnant validity. The factor loadings depicted in the figure fall well within the criteria of Hildebrandt (1987) and Hair (2006) for convergent validity.

Table 5 AMOS generated Model fit indices of measurement model of organizational citizenship behaviour.

\begin{tabular}{lc}
\hline Index & Reported Value \\
\hline Chi square divided by degree of freedom(CMIN/df) & 2.4 \\
Goodness of fitness index ( GFI ) & 0.94 \\
Comparative fit index (CFI) & 0.92 \\
Root mean square error of approximation (RMSEA) & 0.06 \\
\hline
\end{tabular}

The model fit indices that were calculated by application of confirmatory factor analysis as highlighted in the table include the value of CMIN/DF= 2.4 which falls well within the threshold of 1 to 3 mentioned by Carmines and McIver (1981);GFI $=.94 \&$ CFI $=.92$ are both higher than the cut-off value of 0.90 and RMSEA $=.06$ is also below the stringent upper limit of 0.07 as stated by Steiger(2007). 
Table. 6 Discrimnant Validity.

\begin{tabular}{lccc}
\hline Dimension $\rightarrow$ & Helping & Civic Virtue & Compliance \\
\hline Helping & 0.40 & & \\
Civic Virtue & 0.28 & 0.41 & \\
Compliance & 0.21 & 0.13 & 0.41 \\
\hline
\end{tabular}

In the above discriminant validity analysis table values on the diagonal axis represent average variance extracted (AVE) and below diagonal axis are squared correlations rounded off to nearest decimal. Using AMOS, VE has been assessed by the estimations of Standardized Regression Weights of each item to its latent construct by adopting approach of Jyoti and Sharma ( 2012).The discriminant validity of the constructs of Helping, Civic Virtue and Compliance is established as the variances extracted for the constructs are higher than the squared correlations between them.

Table 7. Construct reliability(CR)

\begin{tabular}{lc}
\hline Dimension & Construct Reliability(C.R.) \\
\hline Helping & 0.80 \\
Civic Virtue & 0.67 \\
Compliance & 0.68 \\
\hline
\end{tabular}

CR was computed from squared sum of standardized factor loadings divided by squared sum of standardized factor loadings plus sum of indicator measurement error for the construct. The values don't fall outside the minimum threshold of 0.60 to 0.70 recommended by Peter (1979).The construct reliability of the measure of organizational citizenship behavior is thus high and satisfactory.

\section{CONCLUSION}

As analysis of the data revealed better psychometric properties, the study supports the meaningfulness \& relevance of using Podsakoff's Organizational Citizenship Behavior Scale, in the Asian cultural context with some modifications. The general picture is that forms of citizenship behavior observed in organizational settings hold relatively well across international contexts. Paille (2009) for example found support for a 4-factor model (altruism, civic virtue, sportsmanship, helping others) in the French context. The present study found that the facets of the OCB construct (altruism, courtesy, sportsmanship, civic virtue and conscientiousness) which had been measured in 


\section{Psychometric Properties of Podsakoff's Organizational Citizenship Behaviour Scale in the Asian Context}

the Western literature were also evident in the context of Jammu \& Kashmir but the factor structure was different. Considering that the respondents perceived altruism \& courtesy as the same construct, the obtained factors were named as Helping Behaviour, civic virtue and compliance as per the guidelines of Podsakoff \& Mackenzie(1994) and Khalid(2009).This finding doesn’t leave a question mark over the discriminant validity of the OCB construct but simply reveals its factor structure in context of sample group of the present study. The diversity in the sample as mentioned in the sample description table increases the generalizability of the results of study in various organizational contexts. The study additionally has many managerial implications. Podsakoff and Mackenzie (1994), Podsakoff, et al. (2009) \& (Koys 2001), highlighted that the main positive outcomes of Organizational Citizenship Behaviour are organizational success and performance. In this context, policy makers of the human service organizations should take necessary steps to encourage OCB among employees. For example, Heads of the various departments of University of Kashmir \& S.K.I.M.S Srinagar; Cluster heads of the J \&K bank and administrators of allied organizations may exhibit citizenship behavior themselves in order to communicate to employees that such behaviors are valued by the management/administration. Besides this as the existing literature portrays that personality traits, psychological capital and job satisfaction determine organizational citizenship behavior(Organ,1997; Luthan,2010; Jehad,2011), the human service organizations should make provisions for providing trainings and workshops to their employees aimed at personality and psychological capital development along with designing the policies as per employee needs so as to increase their job satisfaction. In terms of the limitations, our findings are limited to the items used to measure OCB in this particular study. In future research, it will be useful to investigate the psychometric properties of the Podsakoff's scale in diverse and larger samples of professionals.

\section{REFERENCES:}

Alexander,J., Nuchols,B., Bloom,J., \& Lee,S.Y.(1995). Organizational demography and turnover- an examination of multiform and non linear heterogeneity. Human Relations,48(12).1455-1480.

Ali, H., Ismail, M., Rahman, N.A., Kassim, M.K., Zain, R.S.(2009).Organizational Citizenship Behavior Factor Structure among Employees in Hotel Industry. International Journal of Psychological Studies,1(1),16-25.

Bateman, T. S., \& Organ, D. W. (1983). Job satisfaction and the good soldier: The relationship between affect and employee "citizenship." Academy of Management Journal, 26(4), 587-595.

Byrne,B.M.(2001).Structural equation modeling with AMOS :basic concepts,applications \& programming. London Lawrence Erlbaum Press.

Carmines,E.G. \& McIver,J.P.(1981).Analysing models with unobserved variables.In Bohrnstedt,G.W. \& Borgatta,E.F.Social Measurement:Current issues.Beverly Hills:Sage

Farh, J.L., Earley, P.C., \& Lin, S.C.(1997). Impetus for action: A cultural analysis of justice and organizational citizenship behavior in Chinese society. Administrative Science Quarterly, 42, 421-444. 


\section{Psychometric Properties of Podsakoff's Organizational Citizenship Behaviour Scale in the Asian Context}

Garson, D. (2009). Testing of assumptions, Retrieved Dec.2014, from http://faculty.chass.ncsu.edu/garson/PA765/assumpt.htm

Hair,J.F.,Black,W.C.(2006).Multivariate data analysis ( $6^{\text {th }}$ ed.)Prentice Hall

Hildebrandt L (1987). Consumer retail satisfaction in rural areas: A reanalysis of survey data. Journal of Economic Psychology 8:19-42.

Hu L \& Bentler PM (1999). Cut-off criteria for fit indexes in covariance structure analysis: Conventional criteria versus new alternatives. Structural Equation Modelling 6(1):1-55.

Janssens,W.,Sefoko,N.Rooyen,J.V. \& Bostyn,F.(2006).Measuring perceived black economic empowerment in the South African wine industrt.Agrekon,Vol.45(4),381-405.

Ketchen,D.J. ,Donald,J.\& Brrgh,D.(2006).Research Methodology in Strategy and Management.Emerald Book Publishing:Amazon.com.

Law,S.K.,Wong,C. \& Chen,X.Z.(2005).The construct of organizational citizenship behavior: should we analyse after we have conceptualized?, Handbook of organizational citizenship behavior,47-65.Newyork: Nova Science Publishers.

LePine, J.A., Erez, A., \& Johnson, D.E. (2002).The nature and dimensionality of OCB: A critical review and meta-analysis. Journal of Applied Psychology,87,52-65.

Lievens, F., \& Anseel, F. (2004). Confirmatory factor analysis and invariance of an organizational citizenship behavior measure across samples in a Dutch-speaking context. Journal of Occupational and Organizational Psychology, 77, 299-306.

Nguyen,H.N.(2009).The impact of leadership behaviours and organizational culture on knowledge management practices in small and medium enterprises. Ph.D Thesis.Griffith School of Engeenering Science,Environment,Engineering and Technology.

Organ, D. W.,Podsakoff, P. M., \& MacKenzie S. P.(2006). Organizational citizenship behavior: Its nature, antecedents, and consequences. London: Sage Publications.

Organ, D.W. (1988). Organizational Citizenship Behavior:The good soldier syndrome. Lexington, MA:Lexington Books.

Organ, D.W., \& Konovsky, M. (1989). Cognitive versus affective determinants of organizational citizenship behavior. Journal of Applied Psychology, 74,157-164.

Organ, D.W., \& Lingl, A. (1995). Personality, satisfaction, and organizational citizenship behavior. Journal of Social Psychology, 135, 339-350.

Pallant,J.(2007).SPSS survival manual: a step by step guide to data analysis using SPSS for Windows(version 15)/Julie Pallant.Allen \& Unwin.

Podsakoff, N. P., Blume, B. D., Whiting, S. W., \& Podsakoff, P. M. (2009). Individual- and organizational-level consequences of organizational citizenship behaviors: A metaanalysis. Journal of Applied Psychology, 94(1), 122-141.

Podsakoff, P.M., \& MacKenzie, S.B. (1994). Organizational citizenship behaviors and sales unit effectiveness. Journal of Marketing Research, 31, 351-364.

Podsakoff, P.M., Ahearne, M., \& MacKenzie, S.B. (1997). Organizational citizenship behavior and the quantity and quality of work group performance. Journal of Applied Psychology, 82, 262-270.

Podsakoff, P.M., MacKenzie, S.B., Paine, J.B., \& Bachrach, D.G. (2000). Organizational citizenship behavior: A critical review of the theoretical and empirical literature and suggestions for future research. Journal of Management,26,513-563. 